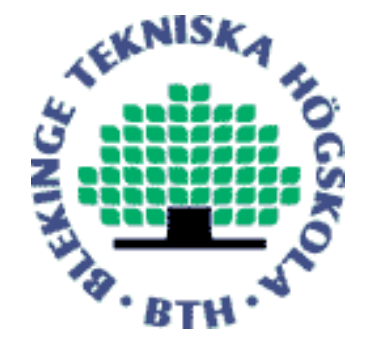

Copyright (C) 2009 IEEE.

Citation for the published paper:

Balancing Software Product Investments

Sebastian Barney, Claes Wohlin, Aybüke Aurum

Empirical Software Engineering and Measurement (ESEM)

2009 Orlando, Florida

This material is posted here with permission of the IEEE. Such permission of the IEEE does not in any way imply IEEE endorsement of any of BTH's products or services Internal or personal use of this material is permitted. However, permission to reprint/republish this material for advertising or promotional purposes or for creating new collective works for resale or redistribution must be obtained from the IEEE by sending a blank email message to pubs-permissions@ieee.org.

By choosing to view this document, you agree to all provisions of the copyright laws protecting it. 
Sebastian Barney, Claes Wohlin, Aybüke Aurum, "Balancing Software Product Investments," Empirical Software Engineering and Measurement (ESEM), October 2009 


\title{
Balancing Software Product Investments
}

\author{
Sebastian Barney \\ Blekinge Institute of Technology \\ Sweden \\ sebastian.barney@bth.se
}

\author{
Claes Wohlin \\ Blekinge Institute of Technology \\ Sweden \\ claes.wohlin@bth.se
}

\author{
Aybüke Aurum \\ School of Information Systems Technology and Management \\ University of New South Wales, Australia \\ aybuke@unsw.edu.au
}

\begin{abstract}
The long-term sustainability of a software product depends on more than developing features. Priorities are placed on aspects that support the development of software, like software product quality (eg. ISO 9126), project constraints - time and cost, and even the development of intellectual capital (IC). A greater focus on any one aspect takes priority from another, but as each aspects delivers a different type of value managers have trouble comparing and balancing these aspects. This paper presents a method to help determine the balance between key priorities in the software development process. The method is applied to a new case study, that also combines with results from previous studies. The results show it is possible to compare features, quality, time, cost and IC in a comprehensive way, with the case study showing that participants perceive a change from a shorter-term product perspective to a longer-term organisation beneficial to the business.
\end{abstract}

\section{Introduction}

The value of developing features for a software product is clear - if a product fails to satisfy the needs of its users the product is worthless. But developing successful and sustainable software requires investment in more than just features, with other investment types requiring time and funding. Extreme Programing (XP) identifies four key areas to control in the development of software [6] -features, quality, time and cost. However, given that software development is human-intensive, it is crucial to also include intellectual capital (IC) when it comes to the investment in and evolution of a software organisation. These areas represent investment types - features, software product quality and $I C$, and project constraints - time and cost.

Ultimately software development managers must be able to balance these investment types and constraints against one another, as an over-investment in any one of these areas will come at the expense of the others - as shown in Figure 1. But people in the software development industry have trouble comparing the importance of the aspects that make up these areas [4]. A hypothetical example would be to ask people to state the relative importance of security, employee satisfaction and delivering on time, which is sure to bring confused faces.

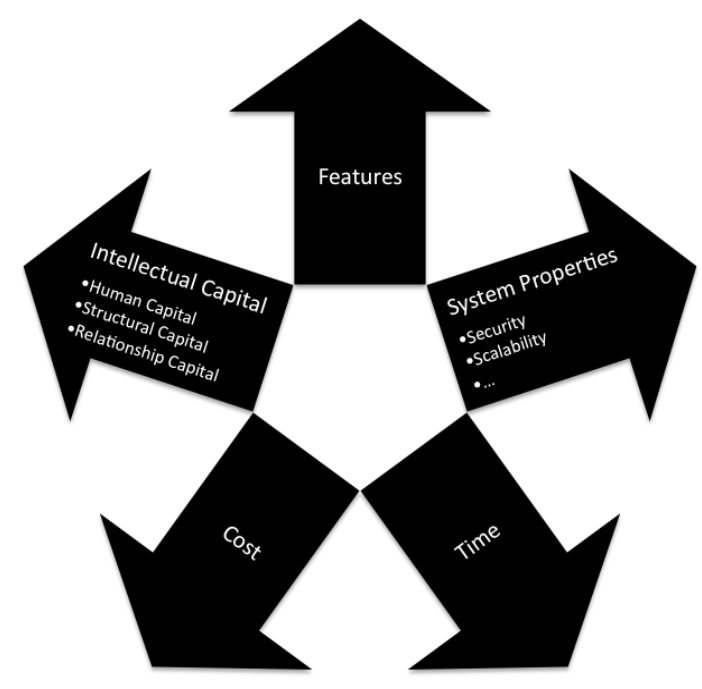

Figure 1. Conflict of Investment Types and Constraints in Software Development

Balancing investment types and constraints is difficult because the investments are intangible, and the aspects be- 
ing examined are interrelated. For example, the act of writing code has the benefit of training the developer - providing benefits both in terms of the feature-base of the software product and the skills of an employee. Managers are interested in knowing the return on investment to be derived from a software product and/or software process improvement, but the value delivered by each investment type differs in who it impacts and how it impacts them. This means value cannot only be considered in monetary terms as there are temporal and human aspects, which make it much harder to make direct comparisons between different types.

Despite any difficulties software development managers may have, they must still make decisions that impact the balance of investment types and constraints. This paper presents a quantitative empirical case study, which combines the results from previously completed studies in the areas of software product quality using ISO 9126 [4] and IC [2] with new data. The extra step presented in this paper allows the previous results to be combined and compared in a comprehensive way, through a single list that shows the relative importance of the aspects that make up features, quality, time, cost and IC. This is the first study to combine these aspects in such a way that they can be compared on a detailed level to the best of the authors' knowledge. This method is used to both describe the current situation within the case study, and any changes the participants perceived ought to occur.

In this paper Section 2 presents an overview of related work and the research questions. Section 3 details the method used to address the research questions. A case study is presented in Section 4, with a discussion of the results and method in Section 5. Threats to the validity are discussed in Section 6. Finally conclusions are drawn in Section 7.

\section{Background}

This section examines the investment types and constraints in more detail, with particular focus on quality and $I C$. Reasons why people have trouble balancing these concerns are discussed along with the reasons why it is important to get this balance right.

\subsection{Investment Types and Constraints}

Literature from XP identifies four variables that need to be controlled in the software development process - features, quality, time and cost [6]. The features are described in terms of functional requirements, while quality is described as non-functional requirements. Constraints on development project time and cost are used to ensure that an economically feasible product is delivered at an appropriate time. However, this view only presents a project and product perspective of software development.

From an organisational perspective, IC must also be considered as an important investment type in the development of sustainable software products, as it is both the key input and tool used in the development of software [30]. IC covers a range of issues from employee training and satisfaction to organisational processes and the knowledge held in the relationships with existing customers.

Thus features and quality present the product perspective; time and cost come from the project perspective; and $I C$ represents the longer-term organisational perspective.

This paper focuses on software product quality and $I C$ in a greater level of detail than the other attributes, as the body of literature covering the prioritisation and selection of features is considerably more established and the project constraints - time and cost - are much more basic. The chosen areas of interest also fall within the scope of the line management position, supporting change within small and focused parts of the organisation. These areas are also of key interest to the authors' industrial partners. Other investment types in the development of software products, such as the location of office space, are outside the scope of this paper.

In most software development organisations resources are limited. This means funding one type of investment will come at the expense of one or more other types of investment, as shown in Figure 1. For example, to deliver a solution on time and budget, with a desired level of quality, it is a common method to exclude the least important features from the release plan.

While it is known that people have trouble comparing the relative importance of these different investment types against one another [4], these are important decisions that managers must face. This only makes understanding the nature of these choices and decision support even more important.

\subsection{Software Product Quality}

Quality is a complex multifaceted concept. Definitions will vary between people, their relationship to the product for which they are describing quality, and the context.

Multidisciplinary research has identified five perspectives from which quality can be described [18]:

- The transcendental perspective defines quality as something that can be recognised but not defined in advance.

- The user perspective defines quality as fit for purpose.

- The manufacturing perspective defines quality as conformance to specification. 
- The product view defines quality in terms of essential characteristics of the product in question.

- The value-based view defines quality in terms of the amount a customer is willing to pay for it.

The user and manufacturer views are the most commonly taken in the development of software [22, 25]. But the increasing body of value-based software engineering (VBSE) literature recognises the importance of taking advantage of all perspectives involved in software development [25]. Central to VBSE is Theory-W [9], which states that success requires all of the success-critical stakeholders to compromise. Similarly requirement specification reading techniques that take advantage of different perspectives have been found to catch $35 \%$ more defects than nondirected alternatives $[5,8]$.

The concept of software quality also changes on the context in which it exists [25]. Software quality must be planned to allow a development company to meet its business objectives. This means that different levels of software quality may be acceptable for software product offerings, just as there is a range of quality when it comes to cars. Less than perfect software quality may be ideal [33], but deciding how much less than perfect can only be decided in a given business context[25].

There are many models that seek to define software product quality. Some examples of these models are McCall's quality model, Boehm's quality model, Dromey's quality model and ISO 9126.

The first of the modern software product quality models was that of McCall [25]. The model uses a hierarchy of factors, criteria and metrics to address internal and external product quality. Eleven factors define an external or user perspective of quality. Each of these factors is linked to between two and five of 23 criteria that define an internal or development perspective of quality. Further metrics are associated with the factors allowing quality to be measured and managed.

McCall's quality model was closely followed by Boehm's quality model [25]. Both models present product quality in a hierarchy, but Boehm's model has three high level characteristics linked to seven intermediate factors, which are in turn linked to 15 primitive characteristics. Boehm's model has a wider scope than that of McCall's, with more emphasis on the cost-effectiveness of maintenance [27].

More recently work has been done to create an international standard for software product quality measurement - ISO 9126 [23]. This standard is again organised in a hierarchy with six characteristics at the top level and 20 sub-characteristics with indicators used to measure the subcharacteristics. In addition to aspects of internal and external quality, covered by McCall's and Boehm's models, ISO
9126 includes quality characteristics of functionality [27]. Internal, external and functional qualities are also mixed at all levels of the hierarchy. However, ISO 9126 does not clearly state how quality should be measured [25].

None of the three models discussed present a rationale for the selection of characteristics to be included in the quality model and it is not possible to tell if a model presents a complete or consistent definition of quality [25]. Further the placement of items are not motivated in ISO 9126, with no justification as to why Interoperability is not related to Portability, for example.

Dromey's model attempts to address some of the issues presented with the other models and support developers achieve software product quality [16]. Dromey states that it is impossible to build high-level quality attributes like reliability or maintainability into a product, but developers must instead build properties that manifest in achieving these goals. The distinction this model makes is important, as using it will verify that it allows the quality required to be achieved [25]. Before Dromey's model can be successfully applied, the various groups involved in the development of a software product must agree on what quality attributes should be achieved and to what level. This process can be supported using other models.

The investment options in software development are more complex than quality, and any quality model must be considered in terms of other options, like $I C$.

\subsection{Intellectual Capital}

The origin of the IC concept can be traced to the balanced scorecard, developed by Skandia - a multinational insurance and financial services company based in Stockholm. Skandia proposed using IC as a management tool for the first time, with an objective to better manage intangible assets when creating further sustainable value for the organisation [12]. Dow Chemical collaborated with Skandia to define the components of IC in terms of human capital, organisation capital and customer capital [24].

Despite attempts to develop a general model of IC, organisations tend to customise models to suit their own context [19].

Four aspects of IC are defined by Brooking [11]: market assets, human centre assets, intellectual property assets and infrastructure assets. Lowendahl [26] identifies intangible assets in terms of competence and relational resources. Sullivan [31] develops a model based on human capital and defines human capital as the capabilities of stakeholders which is supported by structural capital - for example computers and information systems.

Bontis [10] divided IC into human capital, relational capital and structural capital with several indicators that each described. Human capital is the capabilities of individuals 
who provide solutions to customers. These include knowledge, experiences, skills and abilities of employees, combined human ability to solve business problems. Structural capital refers to the structures and processes within the organisation that meets market requirements - for example patents, trademarks, information systems. Relational capital refers to an organisation's relations with stakeholders including customers, suppliers and public. This model is one of the most frequently used models by practitioners and academics.

Previous research and business practices have led to various models and indicators of IC [32, 31, 17].

There are several techniques, systematic processes and models used to measure IC of organisations. These include balanced scorecard, relative value, competency models, subsystem performance, benchmarking, business worth, business process auditing, knowledge bank, brand equity valuation, calculated intangible value, micro-lending, colorised reporting [28].

Over the years, several methods of measuring IC have also been developed. For example Skandia Navigator, Intellectual Capital Services' IC Index ${ }^{\mathrm{TM}}$ and Philip M'Pherson's Inclusive Valuation Methodology $\left(\mathrm{IVM}^{\mathrm{TM}}\right)$ [21]. The starting point of every method is the identification of intellectual assets and grouping of these into categories. For example, Skandia's Navigator model includes 112 indices of IC whereas Edvinsson and Malone measure IC by developing 140 indicators, using four perspectives, namely financial, customer, human, and renewals and development [21].

While many researchers have examined attributes of IC, there appears to have been no systematic attempt in the intellectual, structural or human capital literature to list the attributes that constitute these areas of study until very recently [29, 13]. Most researchers have only examined aspects of these areas, recognising any list of attributes as incomplete. Moon and Kym [29] noted without a clear and comprehensive framework for IC, managers are likely to lack the detail required to effectively manage their organisations' IC, so they created a model of IC by synthesising the attributes and model fragments from many studies. This model is used in this paper.

Measuring IC has several benefits. For example it allows companies to assess the risk present and identify areas to develop and improve, it provides a systematic approach when comparing several units within a company or companies, it provides very useful information on companies' future potential and helps providing a comprehensive company report.

Benefits can be direct, indirect or long term [15]. Direct benefits improve financial performance of the organisation. Indirect benefits are related to changes in elements of performance which may be beneficial for the company - for example motivating staff members which allows managers to be more productive or increase in code reuse or reduction in testing time. Long term benefits include an improvement of the relationships within a company.

Although measurement of IC has several benefits to a company, this is a costly process because of the time needed to collect the data, analyse it and take actions on those measurements. In order to lower the cost, companies may need to automate the measurement and cut down on the number of people involve in the process as in many cases benefits achieved are difficult to quantify [15].

Additionally, the body of knowledge of investment in IC in a software engineering context is limited. The authors found that the majority of literature covers investment issues in software product line practice, and the impact of upfront investment on cumulative return in terms of money, effort and time [20]. Managers need to be able to understand the balance of the various aspects they are managing in order to make informed decisions.

\section{Methodology}

This section presents the research questions, and describes the method to be used to answer them. The approach taken in this paper to answer the research questions is presented in two ways. This section presents the general method, which can be applied to all cases. Section 4 presents the actual steps taken in the case study presented in this paper.

\subsection{Research Objectives}

Finding the right balance between investment types and constraints is critical for the long-term success of all software development organisations. The major investment types come from the product perspective, with issues of features, quality; and from the organisational perspective with issue of $I C$; while time and cost represent the major project perspective constraints. Too much focus on any one of these areas will result in an under-investment in other areas as they compete with each other, as shown in Figure 1.

Getting people to identify the balance between investment types and constraints is a difficult task, but an essential one if these investment options and constraints are going to be successfully managed [4].

Previous research by the authors has sought to find the balance between aspects of individual investment types from a product perspective aspects of software product quality were studied using ISO 9126 [4] and from an organisational perspective aspects of IC were studied [2]. However, these aspects must ultimately be understood and balanced together. The research presented in this paper aims to bring these previous studies together with other feature and 
project perspective constraints, as shown in Figure 2, to understand how these areas interrelate in terms of importance. The areas covered in the case studies are discussed in more detail in Section 4, with a complete listing of the areas in Figure 4.

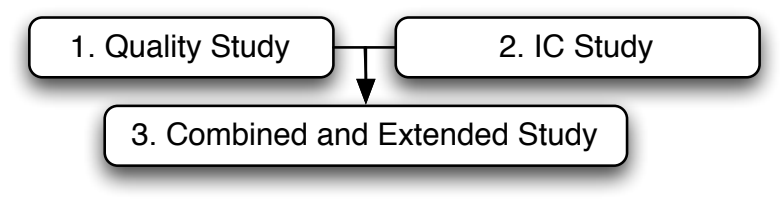

Figure 2. Study Design

Thus the research questions addressed in this paper are:

RQ1: Is it possible to identify the relative importance between aspects of features, software product quality using ISO 9126, the project constraints time cost, and IC for a given situation?

If it is possible to find the relative balance between this aspects, then it is of interest to ask:

RQ2: What is the balance between aspects of features, software product quality using ISO9126, the project constraints time cost, and $I C$ for a given situation today?

However, being able to identify the current balance of investment types does not ensure that the correct balance has been achieved. Thus it is also important to identify what is perceived as the ideal balance for the current situation faced in an organisation. This is addressed by the third research question:

RQ3: What is the perceived ideal balance between aspects of features, software product quality using ISO9126, the project constraints time cost, and $I C$ for a given situation today?

\subsection{Approach}

To address the research questions a method has been developed, expanding on previous work by the authors in quality [4] and IC [2]. The previous studies were conducted to determine the level of alignment between key stakeholder groups over the priorities of aspects of quality and IC respectively, however, they also generated lists showing the relative importance of the aspects related to each study.

The method presented in this section expands on the work already done, to combine the previous results with new data to answer the research questions. While details of the case study are presented in Section 4, this section details a more general methodology to answer the research questions.

The process to determine the balance between different investment options and constraints in this paper has five phases:
1. First identify the investment types and constraints that should be covered, and develop the model.

2. Then associate stakeholder groups to the different parts of the model to identify who should participate in the study.

3. Put together the questionnaires for eliciting the balance of investment types and constraints.

4. The results are analysed.

5. Finally hold a workshop with key stakeholders to develop a deeper understanding of the results.

The following sections explains each of these phases in more detail.

\subsection{Investment Types and Constraints}

The investment types and constraints vary depending on both the organisation and roles studied. Thus it is important that any study tailor the attributes for the context being studied. Using one or more of the quality models and $I C$ models introduced in Section 2 is a good starting point, but company specific needs have to be taken into account, as illustrated in the case study in Section 4.

The selection and refinement of models to represent the investment types and constraints should be a consultative process between academia and industry to ensure that a representative and meaningful result is obtained. A workshop or series of workshop should be run to ensure the terms identified provide sufficient coverage and are clearly defined from the perspective of those participating in the study and those using the results.

However, it is important that the model developed is hierarchical in order to take advantage of the methodology presented in this paper, or flat for a simple case. As an example, the model of investment types and constraints used in the case study presented in this paper can be seen in Figure 4. This model is discussed in more detail in Section 4.

\subsection{Stakeholders}

When considering a range of investment options and constraints, it is likely that no one person or group will have detailed oversight of all of the areas of interest. Managers may be able to provide insight on high-level priorities, but not be able to go into the detail about technical qualities. Similarly a developer may not need to be aware of all of the external stakeholder groups with whom the company has a relationship.

This is where the value of the hierarchy comes into play. It is possible to ask different groups of people to be involved in the prioritisation of different parts of the hierarchy, as the 
method then allows the separate responses to be brought together.

Participants should only be responsible for prioritising parts of the hierarchy for which they have understanding and oversight.

\subsection{Questionnaire}

Now it is possible to develop a questionnaire or series of questionnaires to answer the research questions. As discussing different parts of a hierarchy is confusing in the abstract, a running example will be used in the remainder of this methodology section, based on the model of investment types and constraints in Figure 3.

\begin{tabular}{|c|c|c|c|c|}
\hline Features & Quality & IC & Time & Cost \\
\hline \multicolumn{2}{|c|}{ Human Capital } & Structural Capital & \multicolumn{2}{|c|}{ Relationship Capital } \\
\hline
\end{tabular}

\section{Figure 3. Example Model of Investment Types and Constraints}

The hierarchical cumulative voting (HCV) method [7] is used to elicit the relative importance of the investment option and constraint. This method has been found useful when asking people to make comparisons between areas in which they would normally have trouble [4], as it breaks the problem up into a series of simpler tasks. It also allows different people to respond to different parts of the model of investment types and constraints.

$\mathrm{HCV}$ is made up of a number of cumulative voting (CV) tasks. CV asks participants to spend 1000 points across different sets of aspects to represent their relative influence. Using the top level of the hierarchy in Figure 3, for example, if a participant thought $I C$ does not at all matter today and features was twice as important as quality they might award these qualities zero, 200 and 100 respectively with 700 points distributed amongst the remaining criteria.

Each CV task should contain a logical group of attributes at the same level of abstraction. The master CV task asks participants to compare the top level of the hierarchy. In the example, there would be two CV exercises - the one comparing the three types of $I C$ and the master $\mathrm{CV}$ exercise asking participants to compare the five items in the top level of the hierarchy.

\subsection{Analysis}

Analysing the results of the HCV task will answer the research questions.

The HCV task is analysed in two stages. The first stage looks at each individual CV task to see the relative weight and priority given to each option. The second stage is to combine the results of the individual HCV tasks into a single prioritised list of attributes, allowing comparisons between the $\mathrm{CV}$ tasks.

For the first stage, it is possible to average the points awarded to each aspect. Then each CV task can be analysed individually considering the rank order of the aspects covered and the range of points awarded to the CV set.

The second stage involves using the results of the first stage and converting the sets of $\mathrm{CV}$ tasks making up the $\mathrm{HCV}$ task into a single list of aspects, with each aspect assigned its own relative weighting. Remembering that $\mathrm{HCV}$ has a master CV task, and for each aspect in that master CV task there may be a related set of sub-aspects in their own $\mathrm{CV}$ task. The example in Figure 3 shows a master list containing features, quality, time, cost and $I C$; with another $\mathrm{CV}$ task asking participants to prioritise between three aspects that make up $I C$.

This set up allows the number of points awarded to each aspect in the master list to be multiplied with the number of points awarded to each aspect in the related CV task [7]. To ensure that aspects from CV tasks with many options are not underrepresented and that $\mathrm{CV}$ tasks with few aspects are not over-represented it is also necessary to multiply each of these results by the number of aspects from the non-master $\mathrm{CV}$ task. Finally the set of numbers for each aspect can be scaled so that the sum is 1000 .

For example, if 200 points are awarded to IC and 400 points are awarded to human capital, then:

$$
\begin{gathered}
I C \times \text { human capital } \times \text { number of aspects of } I C \\
=200 \times 400 \times 3 \\
=240,000
\end{gathered}
$$

The scaling of this result then depends on the other values, but if the other values were to sum to $4,800,000$ then the number would be scaled to:

$$
\begin{gathered}
\text { result } \div \text { total sum } \times 1,000 \\
=240,000 \div 4,800,000 \times 1,000 \\
=50
\end{gathered}
$$

It is possible to deal with aspects in the master CV task with no related $\mathrm{CV}$ task, such as features in the running example. In this case create a dummy CV task that contains one item with the same name, and award it 1000 points.

\subsection{Review}

Finally the results should be reviewed with the participating organisation in order to gain a deeper understanding of what the results mean and the reasons behind them. This can be done in a workshop setting. 


\section{Case Study}

This research has grown from two previous case studies that each looked at the relative importance of different aspects related to different investment types - quality [4] and IC [2] - as shown in Figure 2. While the original intent of these studies was to determine the degree to which priorities across the organisation were aligned and working towards a common goal, the results generated lists showing the relative importance of the various aspects that make up each investment type.

There was a desire, both academically and from within the industrial partner, to join these studies together to understand the relative importance of both sets of investment options together with features, time and cost. This is the aim of the study presented in this paper, and involved the collection of additional data and an expansion of the methodology to join these areas together.

This case study was conducted during autumn 2008 for two products at Ericsson. Ericsson is a world leading company in telecommunication, providing a wide range of products and solutions. Products are developed and sold as generic solutions offered to an open market, although customised versions of the products are also developed.

\subsection{Attribute Selection and Definition}

In order to both validate the work previously done, and to be able draw greater understanding from the research, it was decided to reuse the models from the previous research. But there was a desire to understand these concepts in terms of features and the project constraints time and cost, as previously discussed. Combined these areas represented the major concerns of line managers within our case study and formed the base of the model of investment types and constraints, and to the best of the authors knowledge is the first time researchers have attempted to find the balance between these aspects in a software engineering context.

Interview time constraints meant it was not possible to use the models exactly as presented in the previous studies as combining all of these elements resulted in too many aspects to consider, however, as the models used are hierarchical it is possible to move to a higher level of abstraction.

The first author created a new model of investment types and constraints based on the control variables for XP [6] and the models created for the previous research into quality [4] and IC [2]. As per the previous studies, a two-hour workshop was then held with people identified by Ericsson to ensure the new model covers the issues of interest to the organisation, makes sense, and can be understood. Some of the definitions were revised, but no major changes were made to the model.
Figure 4 shows the model of investment types and constraints used across the three studies that make up this research. This study asked participants to complete the master $\mathrm{CV}$ task - comparing features, qualities, time, cost and IC. However, as this study was conducted several months after the first two studies, two additional CV tasks were added to check the priorities had not changed. These consist of the aspects describing quality and $I C$ that are bolded in Figure 4.

The first study asked participants to mark the relative importance of the detailed quality aspects, which are shown in the diagram without bolding. Similarly the second study asked participants to mark the relative importance of the detailed $I C$ aspects, which are also shown in the diagram without bolding.

A questionnaire was developed based on the bolded sections of this model for the third study. One CV task asked participants to compare aspects of $I C$, the second asked participants to compare aspects of software product quality and the final $\mathrm{CV}$ task asked participants to compare features, quality, intellectual capital, time and cost. The final version of the questionnaire with definitions of all of the terms in the model is available online[3].

\subsection{Participant Selection}

The authors were supported by the R\&D management to select and identify participants for this case study. It was decided that people in line management positions would be able to best address the areas of greatest interest to the company from this study. This group also has the greatest control over the balance being studied. However, this limited the number of possible participants as few people hold this role for the products studied. In total nine participants were selected to take part in the case study. The first author conducted one-on-one interviews with each participant to collect the data. These interviews took between 25 minutes and one hour, as per the previous studies. All responses were used in the analysis.

However, as this study combines the results of the previous studies, the number of participants and their roles is presented in Table 1. There is some overlap between the participants in the three studies, but effort was made to include new people in each study who had not previously participated in the research. Note that line managers were interviewed in the quality study, but as these results were grouped with the appropriate organisational unit this job role is not identified. In the combined study the line managers come from the range of organisational units covered in the quality study. 


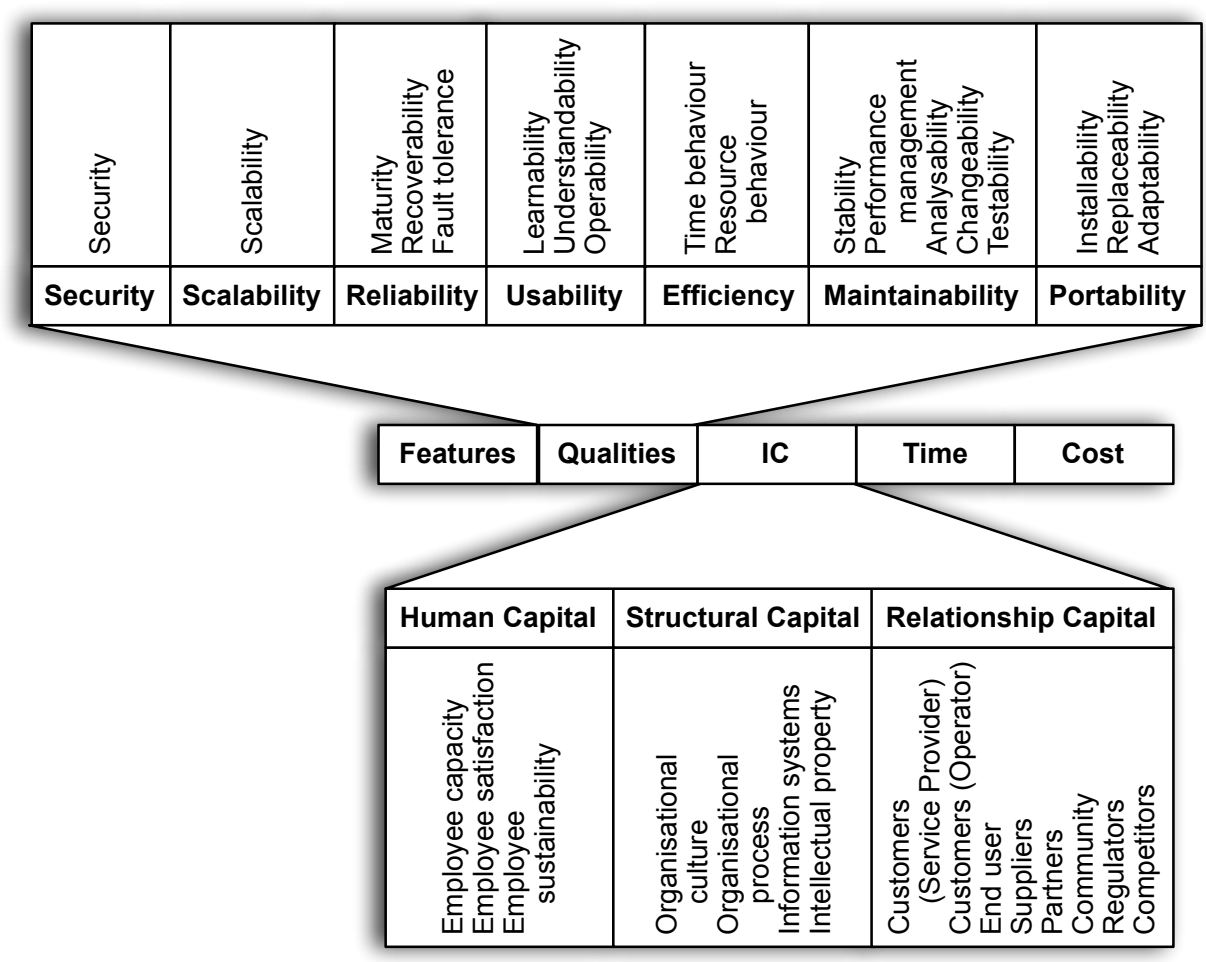

Figure 4. Model of Investment Types and Constraints from Case Study

\section{Table 1. Study Participants}

\begin{tabular}{lrl} 
& \multicolumn{2}{l}{ Participants } \\
\hline Study & No. & Role(s) \\
\hline Quality Study & 31 & $\begin{array}{l}\text { Strategic Product Managers, } \\
\text { Tactical Product Managers, } \\
\text { Project Managers, Developers, } \\
\text { Testers }\end{array}$ \\
IC Study & 32 & $\begin{array}{l}\text { Strategic Product Managers, } \\
\text { Tactical Product Managers, } \\
\text { Project Managers, Line Man- } \\
\text { agers, Developers, Testers }\end{array}$ \\
$\begin{array}{l}\text { Combined \& } \\
\text { Extended Study }\end{array}$ & 9 & Line Managers \\
\hline
\end{tabular}

\subsection{Additional Analysis}

The results of the IC study [2] contained several aspects of management that are outside the scope of this study as they are not directly related with $I C$. In order to manage this situation the aspects of management were removed. The relative weights of the remaining aspects were scaled to 1000 using the same process used in the final stages of the method described in Section 3.

\subsection{Results}

While confidentiality prevents the prioritised list of attributes being published, the results are described and discussed in this section.

The results were fairly consistent between the participants for the additional data collected as part of the combined and extended study, with one exception that is discussed in this section.

\subsubsection{Comparison to Previous Studies}

This research aims to bring the results of three studies together. As there were some months between the collection of data for each study, some additional data was collected 
about aspects of quality and IC to ensure that the situation had not changed substantially between data collection points.

The quality study collected data about the 18 aspects of quality listed at the top of Figure 4. This study collected data about the six aspects of quality listed in the same figure in bold. The results of both studies showed strong parallels for both what people perceive is happening today and what people perceive should be happening in an ideal situation.

Similarly it was possible to make a comparison between this study and the $I C$ study based on the three main areas of $I C$ shown in bold at the bottom of Figure 4, as both studies used HCV in similar ways. The averaged results for line managers in both studies placed these three aspects in the same order in both the situation today and the ideal situation.

\subsubsection{Overall}

Looking first at the prioritisation of the $\mathrm{CV}$ group containing features, quality, time, cost and intellectual capital there are a couple of interesting results. These results are presented in Table 2.

\section{Table 2. Priorities on Investment Types and Constraints}

\begin{tabular}{ll}
\hline Today & Ideal \\
\hline 1. Features & 1. Time \\
2. Time & 2. Features \\
3. Quality & 3. Intellectual Capital \\
4. Cost & 4. Quality \\
5. Intellectual Capital & 5. Cost \\
\hline
\end{tabular}

The results show that success is most dependent on delivering features within some constraint of time, with these two aspects coming out most important in the situation as it is perceived today, and how the participants would like to see the situation today.

However, some change was perceived beneficial to the situation today in the perceived ideal situation. The participants would ultimately like to see a stronger focus on intellectual capital. Additionally the participants would like to see a more equal focus on the different aspects, with a difference of 196 points between the most and least important aspects today, and a difference of 41 points in the perceived ideal situation.

It should be noted that participants were not consistent with their prioritisation of all five aspects, with quality being placed anywhere between most important to least important by different participants. The level of agreement on the other aspects in this group was much higher for the situation today. While the level of consensus was lower in how the participants prioritised what should be happening in the ideal situation today, the differences between the aspects studied was quite small.

\subsubsection{Detailed Priorities}

Using the method described in Section 3 the three CV results from the three studies were used to create a single list covering 36 aspects of investment types and constraints features, all 18 aspects of quality, time, cost and all 17 aspects of $I C$. These can be seen in Figure 4.

In describing the situation today, the results show a strong product perspective, although the project perspective is important with respect to time. The top 10 aspects consist of eight different aspects of quality, features and time - suggesting the organisation likes to deliver functional requirements to schedule, with a certain set of quality requirements being met. The remainder of the slit evenly across the different aspects, with no investment type group standing out.

It is worth noting that the two most important aspects of IC today represent the customer, with customer (operator) and customer (service provider). The third most important aspect of IC today is organisational process.

Participants were also asked to complete the tasks to show what they think should be happening today, in their perceived ideal situation. These results show no clear preference for any one investment type except features, which remains with a relatively high priority.

Ideally there are aspects of both quality and $I C$ at the top, middle and bottom of the prioritised list. Looking at the difference in ranking between the situation today and the perceived ideal situation there are a number of interesting results:

- All but one of the aspects that participants identified should have a higher rank in the ideal situation were aspects of $I C$. In particular they were mostly aspects of human capital and relationship capital.

- A greater focus on the end user is one of the biggest changes desired.

- The aspects that fell the greatest number of places were from quality, but to a more limited extent features and time also fell.

- One aspect of $I C$ fell a notable number of places. It was organisational process.

The results also show that the participants would ideally like the aspects to be more equal in their relative priority. In describing the situation today the most important aspect received 57 points and the least important aspect received 
nine, giving a difference of 48 points. However, in the ideal situation there were only 27 points between the most and least important aspects as everything was brought closer together.

\section{Discussion}

The method presented in Section 3 appears to be robust. The method was able to combine priorities from the product, project and organisational perspectives - showing the relative importance of different aspects that make up features, quality, time, cost and IC.

The results of the case study show a strong product perspective within the organisation, with features and quality coming out as the most important investment types today. However, there is still a strong customer focus in terms of the priorities within $I C$.

Ultimately the participants in the case study would like to see a stronger organisational perspective taken, with a much greater emphasis on aspects of human capital and relationship capital. This means taking a longer-term focus when balancing the investment types and constraints against one-another, and being able to deliver value to customers both now and in the future. This result can be partially explained by a restructure within the organisation studied and the economic downturn. Both of these events act to make people feel less secure about their jobs, and the results show a desire for greater security and respect.

The one aspect of $I C$ that bucked the trend set by all other was organisational process. Ideally the participants thought this should be less important. However, the organisation studied had also come to the same conclusion, and reducing processes and decision points was one of the major goals of the restructuring.

The perceived ideal situation remained customer focused, but saw a big increase in the importance of the end user. The end user in this case Ericsson's customers' customers.

The results of the third study, involving line mangers, was interesting in that no major changes were proposed by the participants. This result is not entirely unexpected from a group of people in line management positions. This result is supported by the garbage can model [14], which found that managers try to address issues with change, rather than solutions, and prefer to take smaller steps rather than bigger ones.

In the case study as it was described today there were 48 points between the most and least important aspects. The description of the perceived ideal situation, however, only had 27 points between the least and most important aspects. There are two possible explanation for this outcome; either the participants believe that the various aspects should be more equal in importance, or when presented with a list of important things, there is a desire to make everything more equal. This result has also been seen in previous studies [1, 4], but there is at least one exception [2].

Finally, communication is critical for the groups involved in the development of software to work together effectively. Knowledge and priorities need to be shared and reconciled, as proposed by Theory-W [9].

\section{Validity Threats}

While it may not be possible to generalise the results of the case study presented in this paper to other organisations, or even Ericsson as a whole, the method shows potential for reuse in other settings. The authors' research has found people have trouble making comparisons between aspects of different investment types [4], however, the approach used in this paper was able to balance aspects of $I C$ against prod$u c t$ and project perspective issues.

It should be noted that it is easier for the participants to agree with the set of criteria identified by the researchers than disagree in the workshops and questionnaire. This threat is partially taken care of by allowing the participants to assign a relative importance of zero to any aspect or set of aspects.

It is also difficult to know whether the respondents have understood the questions as intended and in a similar fashion to one another. This threat was partially addressed in the third stage of this study where the results were presented in the second workshop for confirmation and discussion with the researcher.

\section{Conclusion}

Being able to balance different investment types within the bounds of certain constraints is a difficult task for software managers, but one that must be undertaken on a daily basis. In this paper the authors presented a method for determining the balance between different aspects of the software development process. The method brought together the results of three separate studies, and examined the balance between:

- The product perspective - with features and software product quality,

- The project perspective - with time and cost, and

- The organisational perspective - with $I C$.

The method proposed in Section 3 was successfully applied to a complex case, thus answering $R Q 1-$ it is possible to identify the relative importance between aspects of features, software product quality using ISO9126, the project 
constraints time cost, and $I C$ for a given situation using the method proposed.

Thus the method was also able to answer $R Q 2$ and $R Q 3$ for this case. That is $R Q 2$ - What is the balance between aspects of features, quality, time, cost and IC for a given situation today? - and RQ3 - What is the perceived ideal balance between aspects of features, quality, time, cost and IC for a given situation today?

The answers resulted in a number of interesting findings:

- The organisation studied currently has a product focus in the priority placed on the aspects studied, but ultimately the participants would like to see a stronger organisational focus - with more emphasis on longerterm issues.

- The results of the study targeted at people in line management positions showed only a desire for small changes, which is inline with research into management practices [14].

The results of this method can be used to start a dialogue within the organisation to ensure all success-critical stakeholder groups understand what activities and investments must be made in order for a company to achieve long term prosperity and sustainability. This will in turn help the different groups within the company work towards and achieve a common goal.

Going forward it is important to understand if the participants in the study have an organisational or individual perspective. While improving the work environment for employees will bring benefits to the organisation to a point, the right balance needs to be achieved between these aspects.

It is also essential to understand what stops organisations from achieving their ideal state, so that they can be supporting in reaching these end goals.

\section{Acknowledgements}

We would like to thank Ericsson for their active involvement in and support of this research.

This work was partly funded by The Knowledge Foundation in Sweden under a research grant for the project Blekinge Engineering Software Qualities (BESQ).

\section{References}

[1] S. Barney, A. Aurum, and C. Wohlin. A product management challenge: Creating software product value through requirements selection. Journal of Systems Architecture, 54(6):576-593, 2008.

[2] S. Barney, A. Aurum, and C. Wohlin. Balancing aspects of intellectual capital. In EUROMICRO Conference on Software Engineering and Advanced Applications (SEAA), August 2009.
[3] S. Barney and C. Wohlin. Software product value and intellectual capital questionnaire. http://www.bth.se/tek/aps/sba, 2008.

[4] S. Barney and C. Wohlin. Software product quality: Ensuring a common goal. In Q. Wang, R. Madachy, and D. Pfahl, editors, Proceedings of the International Conference on Software Process (ICSP), pages 256-267, May 2009.

[5] V. R. Basili. Evolving and packaging reading technologies. Journal of Systems and Software, 38(1):3-12, 1997. Achieving Quality in Software.

[6] K. Beck. Extreme Programming Explained: Embrace Change. Addison-Wesley, Reading, Massachusetts, 2000.

[7] P. Berander and P. Jönsson. Hierarchical cumulative voting (hcv) - prioritization of requirements in hierarchies. International Journal of Software Engineering and Knowledge Engineering, 16(6):819-849, December 2006.

[8] B. Boehm and V. Basili. Software defect reduction top 10 list. Computer, 34(1):135-137, January 2001.

[9] B. Boehm and R. Ross. Theory-w software project management principles and examples. IEEE Transactions on Software Engineering, 15(7):902-916, 1989.

[10] N. Bontis. Assessing knowledge assets: a review of the models used to measure intellectual capital. International Journal of Management Reviews, 3(1):41-60, 2001.

[11] A. Brooking. Intellectual Capital: Core Asset for the Third Millennium. Cengage Learning EMEA, 1998.

[12] M. Bucklew and L. Edvinsson. Intellectual capital at skandia. The Foundation for Performance Measurement, 1999.

[13] E. Carson, R. Ranzijn, A. Winefield, and H. Marsden. Intellectual capital: Mapping employee and work group attributes. Journal of Intellectual Capital, 5(3):443-463, 2004.

[14] M. D. Cohen, J. G. March, and J. P. Olsen. A garbage can model of organizational choice. Administrative Science Quarterly, 17(1):1-25, March 1972.

[15] Cranfield. A report on the costs and the benefits of measuring intellectual capital assets. Technical report, Cranfield University School of Management, 2004.

[16] R. Dromey. Concerning the chimera. Software, IEEE, 13(1):33-43, January 1996.

[17] L. Edvinsson. Developing intellectual capital at skandia. Long Range Planning, 30(3):320-321, 366-373, 1997.

[18] D. A. Garvin. What does "product quality" really mean? Sloan Management Review, 26(1):25-43, 1984.

[19] D. Han and I. Han. Prioritization and selection of intellectual capital measurement indicators using analytic hierarchy process for the mobile telecommunications industry. Expert Systems with Applications, 26(4):519-527, 2004.

[20] W. A. Hetrick, C. W. Krueger, and J. G. Moore. Incremental return on incremental investment: Engenio's transition to software product line practice. In OOPSLA '06: Companion to the 21st ACM SIGPLAN symposium on Object-oriented programming systems, languages, and applications, pages 798-804, New York, NY, USA, 2006. ACM.

[21] T. J. Housel and A. H. Bell. Measuring and managing knowledge. McGraw-Hill/Irwin, Boston, Mass., 2001.

[22] R. W. Hoyer and B. B. Y. Hoyer. What is quality? Quality Progress, 34(7):53-62, July 2001. 
[23] ISO9126. Software engineering - product quality - part 1: Quality model. International Standards Organization, 2001.

[24] A. Jashapara. Knowledge Management: An integrated Approach. Financial Times Prentice Hall, Harlow, 2004.

[25] B. Kitchenham and S. Pfleeger. Software quality: The elusive target. IEEE Software, 13(1):12-21, January 1996.

[26] B. Lowendahl. Strategic Management of Professional Services Firms. Handelshöjskolens Forlag, Copenhagen, 1997.

[27] D. Milicic. Software Quality Attributes and Trade-Offs, chapter Software Quality Models and Philosophies, pages 3-19. Blekinge Institute of Technology, 2005.

[28] Montague. Measuring intellectual capital. Technical report, Montague Institute, 2008.
[29] Y. J. Moon and H. G. Kym. A model for the value of intellectual capital. Canadian Journal of Administrative Sciences, 23(3):253-269, September 2006.

[30] G. Roos and J. Roos. Measuring your company's intellectual performance. Long Range Planning, 30(3):325, 413-426, 1997.

[31] P. H. Sullivan. Profiting from intellectual capital: Extracting value from innovation. Wiley, New York, 1998.

[32] K.-E. Sveiby. Intellectual capital and knowledge management. Technical report, Sveiby Knowledge Management, 1998.

[33] E. Yourdon. When good enough software is best. IEEE Software, 12(3):79-81, May 1995. 